\title{
Configuraçôes familiares e implicaçôes para o trabalho em saúde da criança em nível hospitalar
}

\author{
I ${ }^{1}$ Élida Fluck Pereira Neto, ${ }^{2}$ Márcia Ziebell Ramos, \\ ${ }^{3}$ Esalba Maria Carvalho Silveira I
}

Resumo: A família tem passado por diversas transformações ao longo do tempo. Hoje, é possível ver diferentes configurações familiares, incluindo, além da família nuclear, tios, avós, padrinhos e mesmo amigos. Esses grupos caracterizam-se por relaçōes de influência recíproca, direta, intensa e duradoura, interiorizadas por seus membros. No trabalho em saúde, especialmente na área de Saúde da Criança, encontram-se trabalhadores, pacientes e famílias. Este estudo buscou, portanto, investigar se os profissionais de saúde identificam implicações das diferentes configuraçôes familiares em seu trabalho. A pesquisa, qualitativa de cunho exploratório, foi realizada na internação pediátrica de um hospital universitário. Os participantes, selecionados por conveniência, foram profissionais das oito formaçôes de nível superior atuantes na unidade: médico, psicólogo, fisioterapeuta, assistente social, farmacêutico, educador físico, nutricionista e enfermeiro. Os dados foram coletados por meio de entrevistas semiestruturadas e interpretados através da análise de conteúdo. Os resultados foram agregados em quatro categorias: "O conceito de família", "A função da família”, "A configuração familiar mais frequente" e "Implicaçōes para o trabalho em saúde". Identificou-se que os trabalhadores reconhecem a presença de diferentes arranjos familiares e sofrem quando identificam demandas que vão além do trabalho prescrito, como exercer as funções materna e paterna.

> Palavras-chave: configurações familiares; trabalho em saúde; saúde da criança.

\author{
1 Centro de Estudos da Família e \\ do Indivíduo. Porto Alegre-RS, \\ Brasil (elidafpneto@gmail.com). \\ ${ }^{2}$ Hospital de Clínicas de Porto \\ Alegre (Psicologia). Porto \\ Alegre-RS, Brasil (mramos@ \\ hcpa.edu.br). \\ ${ }^{3}$ Hospital de Clínicas de Porto \\ Alegre (Serviço Social). Porto \\ Alegre-RS, Brasil (esilveira@ \\ hcpa.edu.br).
}

Recebido em: 13/08/2015 Aprovado em: 18/01/2016 
A família tem passado por diversas transformações desde a Idade Média. Essas transformações decorrem da reciprocidade entre fatos históricos e suas repercussões na subjetividade do homem, que tanto é marcado pelos acontecimentos como é provocador destes (ROUDINESCO, 2003).

Dentre as diversas disciplinas que estudam o tema, a Psicologia entende a família como um conjunto de relações caracterizadas por influência recíproca, direta, intensa e duradoura entre seus membros (DE ANTONI, 2005). Esse conjunto de relações é interiorizado por seus membros, formando padrões de relacionamento que se integram à subjetividade do indivíduo (ROUDINESCO, 2003).

Os diferentes arranjos familiares surgiram do modo como se dispõem e se relacionam os membros do grupo, tanto entre si quanto com a sociedade (PAPALIA; FELDMAN, 2013). A família, portanto, é uma entidade flexível e permeável à sociedade, sendo necessário considerar aspectos como demografia, vida privada, papéis familiares, relaçôes entre Estado e família, lugar, parentesco, transmissão de bens, ciclo vital da família e rituais de passagem (HINTZ, 2007).

Roudinesco (2003) identifica três fases da família: a família tradicional, a família moderna, do final do século XVIII, e a família contemporânea, a partir da década de 1960. Desde a família tradicional, com casamentos arranjados, cujo objetivo era a transmissão de patrimônio, a instituição foi progressivamente estabelecendo relações mais igualitárias, fundamentadas na livre escolha dos cônjuges e no amor conjugal (TRAD, 2010).

Podem-se destacar as transformações sociais, culturais e econômicas de meados do século XX como importantes desencadeadoras dessas alterações estruturais e dinâmicas (OLIVEIRA et al., 2008). As guerras mundiais, a consequente entrada da mulher no mercado de trabalho e os movimentos feministas deram origem à família moderna e favoreceram essa reestruturação.

Outra modificação da família moderna refere-se à quantidade de membros pertencentes ao sistema, tornando-se tendência a diminuição do número de pessoas que compõem o grupo familiar (VILLA, 2012). Da convivência entre pais, filhos, outros parentes e empregados, no início do século $\mathrm{XX}$, passou-se à convivência, essencialmente, de pais e filhos, ou seja, a família nuclear, que ainda se baseava na autoridade patriarcal. 
A partir dos anos 1960, no entanto, influenciada pela reconhecida importância da vida privada, surge a família agora chamada de contemporânea ou pósmoderna. Ela une, por determinado período de tempo, dois indivíduos que têm por objetivo relações íntimas ou realização sexual, reduzindo o impacto das concepções patriarcais de organização familiar (ROUDINESCO, 2003).

Em decorrência desse processo evolutivo, a família, hoje, é resultado da combinação de diferentes papéis e padrōes relacionais, baseados na valorização da solidariedade e da fraternidade, na ajuda mútua e nos laços de afeto e de amor (HINTZ, 2007). No cotidiano, é possível encontrar famílias seguindo modelos nucleares, casais dividindo os cuidados dos filhos e da organização familiar, mulheres e homens assumindo, independentes, o sustento da família (monoparentalidade) (OLIVEIRA et al., 2008; OLIVEIRA, 2009), uniōes consensuais de parceiros separados ou divorciados (LOBO, 2009), casais sem filhos, casais homossexuais, casais com filhos adotivos, avós com os netos, associações - grupos de pessoas não consanguíneas, normalmente amigos, que moram juntos - e uma grande variedade de formas a serem definidas (HINTZ, 2007).

Tendo em vista essas considerações, destaca-se a centralidade da família para o desenvolvimento humano individual e social (BOWLBY, 2006). É na família que a criança encontra o principal espaço de socialização, influenciando na aquisição de habilidades, comportamentos e valores contextualizados culturalmente. A família, portanto, caracteriza-se como parte essencial da construção de saúde emocional de seus membros, primando por sua proteção e bem-estar (MINUCHIN, 1982). Desse modo, a centralidade da família permanece vigente, independentemente da configuração que assume na contemporaneidade.

Essa importância se evidencia na tendência das políticas de saúde e de assistência social em articularem serviços voltados à família e à própria comunidade (OLIVEIRA, 2009). A Estratégia Saúde da Família (ESF) é um exemplo desse apontamento (TRAD, 2010), sendo considerada prioridade para expansão e consolidação da atenção primária no Brasil (BRASIL, 2012).

No nível de atenção de alta complexidade, pode-se exemplificar a concretização dessa tendência através do Estatuto da Criança e do Adolescente (ECA), no seu artigo 12: "Os estabelecimentos de atendimento à saúde deverão proporcionar condiçôes para a permanência em tempo integral de um dos pais ou responsável, nos casos de internação de criança ou adolescente" (BRASIL, 1990). A 
Declaração dos Direitos da Criança e do Adolescente Hospitalizados (BRASIL, 1995) também merece destaque, por versar, nos artigos $4^{\circ}$ e $5^{\circ}$, respectivamente, sobre o direito de "não ser separado de sua mãe ao nascer" e de "ser acompanhado por mãe, pai ou responsável durante todo o período de sua hospitalização, bem como receber visitas".

Em relação à saúde, a legislação busca responder à situação de adoecimento, experimentada coletiva e não individualmente (ROMANO, 2008). Nos casos em que o membro da família hospitalizado é uma criança ou um adolescente, o afastamento do convívio familiar pode aumentar a fragilidade do paciente e dificultar a sua recuperação (FAVARATO; GAGLIANI, 2008). Dessa situação, emerge a necessidade de um cuidado prestado não apenas ao paciente, mas também à família (OLIVEIRA; SOMMERMAN, 2008), que vem ao hospital com um arranjo próprio, representativo da multiplicidade de formações possíveis. Assim, as novas configuraçôes familiares demandam dos profissionais que trabalham diretamente com a instituição família uma busca ativa na compreensão de tais mudanças (OLIVEIRA, 2009). Com efeito, isso repercute diretamente no trabalho realizado no campo da saúde.

$\mathrm{Na}$ área de saúde da criança, como vimos, o trabalho implica necessariamente o envolvimento da família, que passa, juntamente com o paciente, a compartilhar o seu cuidado com a equipe de saúde (GOMES; OLIVEIRA, 2012). No contexto hospitalar, em determinados momentos, existe uma forte tendência a perceber paciente e família a partir de uma visão dicotomizada (SOUSA et al., 2011). Porém, o compartilhamento dos processos de cuidado entre trabalhador e família é um dos dispositivos de humanização deste ambiente. Compreender a experiência de hospitalização para a família favorece uma reflexão sobre estratégias possíveis que favoreçam vivências produtivas e menos traumáticas (GOMES; OLIVEIRA, 2012).

Considerando o exposto, destacamos o trabalho em saúde como um encontro entre sujeitos, produzindo subjetividades e disparando modos de viver e sentir o trabalho. Tais modos de subjetivação têm como fator contribuinte nesse processo as transformações da família, expressas através dos diferentes arranjos familiares. O cenário em questão, uma unidade de internação pediátrica de um hospital público, demanda do trabalhador um olhar ampliado e um cuidado direcionado à família, e não apenas a ele. 


\section{Objetivo}

Investigar se os profissionais de saúde identificam efeitos das diferentes configurações familiares em seu trabalho em saúde junto aos pacientes da internação pediátrica de um hospital universitário de Porto Alegre.

\section{Método}

A pesquisa realizada foi qualitativa, de cunho exploratório. ${ }^{1}$ Os dados foram coletados por meio de entrevistas semiestruturadas realizadas na internação pediátrica de um hospital geral. O hospital possui duas unidades de internação pediátrica, com capacidade para atender 63 pacientes. As questões que compunham o instrumento eram: 1) Para você, o que é uma família? 2) Qual o papel da família na vida da criança e do adolescente?; 3) Qual a configuração familiar mais presente na internação pediátrica do hospital onde você trabalha?; 4) Você considera que as diferentes configurações familiares podem ter implicações no desenvolvimento do trabalho em saúde? De que maneira?; e 5) Você lembra de alguma situação, no seu trabalho com as famílias, que tenha sido significativa? Qual?

Após a coleta, as entrevistas foram transcritas e interpretadas através da análise de conteúdo (BARDIN, 1979). Foram consideradas para análise, juntamente com as categorias empíricas geradas pela análise dos dados, as categorias teóricas prévias (MINAYO; GOMES; DESLANDES, 2008): família, configurações familiares, trabalho e trabalho em saúde. As categorias foram escolhidas conforme a temática da pesquisa. $\mathrm{Na}$ apresentação dos resultados, os participantes são identificados com a letra $p$.

O hospital conta com a atuação de profissionais de oito diferentes graduações em sua equipe de atendimento. Todas foram incluídas na amostra, que foi selecionada por conveniência. Cada participante provinha de alguma das seguintes formações de nível superior: médico, psicólogo, fisioterapeuta, assistente social, farmacêutico, educador físico, nutricionista e enfermeiro. Os enfermeiros exerciam suas atividades profissionais em apenas uma das duas unidades de internação onde os dados foram coletados. Devido às diferenças no perfil de pacientes internados em ambas as unidades (especialmente em relação à faixa etária), foi selecionado um enfermeiro de cada unidade. A amostra, portanto, foi composta por nove profissionais com, no mínimo, um ano de atuação na unidade. Outros dados de caracterização da amostra são apresentados na tabela 1 . 


\begin{tabular}{l|l|l|l|l}
\hline N & $\begin{array}{l}\text { Experiência em } \\
\text { pediatria } \\
\text { (média em anos) }\end{array}$ & $\begin{array}{l}\text { Atuação no hospital da } \\
\text { coleta de dados (média } \\
\text { em anos) }\end{array}$ & $\begin{array}{l}\text { Pós- } \\
\text { graduação } \\
(\text { sim })\end{array}$ & $\begin{array}{l}\text { Sexo } \\
(\mathbf{n})\end{array}$ \\
\hline $\mathbf{9}$ & $\begin{array}{l}\text { 13,6 (mínimo: } 2 \text { anos; } \\
\text { máximo: } 40 \text { anos) }\end{array}$ & $\begin{array}{l}10,5 \text { (mínimo: } 2 \text { anos; } \\
\text { máximo: 38 anos) }\end{array}$ & $100 \%$ & $\begin{array}{l}\text { Feminino: } 8 \\
\text { Masculino: } 1\end{array}$ \\
\hline
\end{tabular}

Em relação às questôes éticas, a presente pesquisa foi aprovada pelo Comitê de Ética em Pesquisa do hospital no qual foi realizada. Os participantes, após esclarecidos sobre o estudo, leram e assinaram o Termo de Consentimento Livre e Esclarecido (TCLE) antes da realização das entrevistas.

\section{Resultados}

O material coletado foi analisado e os resultados agregados em quatro categorias, conforme a tabela 2 .

\section{Tabela 2. Categorias}

\begin{tabular}{|c|c|c|}
\hline Categorias & Descriçãoo & Exemplos \\
\hline $\begin{array}{l}\text { O conceito } \\
\text { de família }\end{array}$ & $\begin{array}{l}\text { Definição do } \\
\text { conceito de } \\
\text { família. }\end{array}$ & $\begin{array}{l}\text { "É um grupo de pessoas que tem algum tipo de ligação } \\
\text { entre elas, uma ligação afetiva ou não. Pode ser uma } \\
\text { organização, uma ligação financeira, mas é um grupo } \\
\text { de pessoas basicamente. (p7)" }\end{array}$ \\
\hline $\begin{array}{l}\text { A função da } \\
\text { família }\end{array}$ & $\begin{array}{l}\text { As funções } \\
\text { que a família } \\
\text { exerce no } \\
\text { desenvolvimento } \\
\text { infantil. }\end{array}$ & $\begin{array}{l}\text { "Acho que é fundamental no papel de desenvolvimento, } \\
\text { de criar laços, de criar educação, em todos os sentidos. } \\
\text { Apoio, suporte, comida, casa, tudo isso é papel da } \\
\text { família. (p8)" }\end{array}$ \\
\hline $\begin{array}{l}\text { A } \\
\text { configuração } \\
\text { familiar } \\
\text { mais } \\
\text { frequente }\end{array}$ & $\begin{array}{l}\text { O arranjo } \\
\text { familiar mais } \\
\text { frequente } \\
\text { dos pacientes } \\
\text { internados } \\
\text { nas unidades } \\
\text { pediátricas do } \\
\text { hospital geral. }\end{array}$ & $\begin{array}{l}\text { "Mais comum eu acho que é os pais dos bebês, ou a mãe } \\
\text { do bebêe, morando com seus pais e irmãos, juntos, assim. } \\
\text { Não é o mais comum o pai, a mãe e os filhos. Acho que é } \\
\text { mais esses agregados, assim. (p3)" } \\
\text { "Eu acho que o mais comum é ver uma família } \\
\text { desestruturada, no sentido de ver uma pessoa só } \\
\text { responsável pela criança, geralmente a mäe ou a vó. (p8)" }\end{array}$ \\
\hline
\end{tabular}

continua... 


\begin{tabular}{|c|c|c|}
\hline $\begin{array}{l}\text { Implicações } \\
\text { para o } \\
\text { trabalho em } \\
\text { saúde }\end{array}$ & $\begin{array}{l}\text { As implicações } \\
\text { das diferentes } \\
\text { configurações } \\
\text { familiares para } \\
\text { o trabalho } \\
\text { em saúde da } \\
\text { pediatria. }\end{array}$ & $\begin{array}{l}\text { "Eu acho que a gente aprende a lidar com isso [...] } \\
\text { E eu acho que a gente vai se adaptando a esse olhar } \\
\text { diferente dessas novas configuraçôes familiares que se } \\
\text { tem. Bom, tivemos já diferentes configuraçôes aqui } \\
\text { [...] Mas eu acho o principal é isso, é poder ver essa } \\
\text { referência e o quanto ela vai poder desenvolver esse } \\
\text { papel protetivo e afetivo com essa criança. (p4)" } \\
\text { "Eu acho que o que dá dificuldade é tu não ter o apoio } \\
\text { familiar. (p1)" }\end{array}$ \\
\hline
\end{tabular}

A definição de família, em diversos momentos, foi associada a sua função diante de seus membros. A primeira e a segunda categorias, portanto, apresentam, entre si, importante relação.

\section{Categoria 1 - O conceito de família}

Na primeira categoria, os participantes destacaram, inicialmente, as mudanças na definição de família ao longo do tempo. A família foi definida, nesta categoria, como um grupo de pessoas unido pela convivência e pelo parentesco. Os profissionais descreveram a família tradicional, nuclear, com pai, mães e filhos, mas também incluíram membros da família extensa, como avós e tios.

Desse modo, vão ao encontro da categoria teórica pré-estabelecida "Configurações Familiares", na qual as diferentes configurações são definidas como o conjunto de personagens que compõem o núcleo familiar (WAGNER, 2011). Assim, levam em consideração as famílias tradicionais, mas também identificam arranjos familiares mais contemporâneos, como famílias extensas, monoparentais e reconstituídas.

Em referência às atuais famílias, os profissionais entrevistados também consideraram como núcleo familiar pessoas que apresentam uma relação de reciprocidade e cuidado mútuo, podendo ser identificados como vizinhos, amigos, padrinhos e madrinhas. Nesse sentido, as relações familiares vão além da consanguinidade:

Eu tenho procurado ver muito o lado da família como sendo não só aquelas pessoas que têm um laço de consanguinidade, mas sim que de alguma forma estabelecem uma relação de cuidado mútuo (p4). 
Essa ideia converge com o conceito proposto na categoria teórica de análise "Família", que caracteriza as relações familiares pela influência recíproca, direta, intensa e duradoura entre seus membros (DE ANTONI, 2005). A fala a seguir demonstra como a noção de família transita entre o antropológico e o sociológico, na medida em que referencia a consanguinidade e o parentesco, e a perspectiva psicológica de família, na qual a família é um conjunto de relaçôes interiorizado por seus membros, formando padrōes de relacionamento (ROUDINESCO, 2003).

[...] uma família de evolução geral é composta pelos pais, pelos familiares anteriores e pelos filhos. Agora, uma família não necessariamente tem que ser dessa forma, muitas vezes são pessoas que acabam vivendo como uma família (p5).

Corroborando esses resultados do ponto de vista infantil, um estudo realizado por Dessen e Ramos (2010) com 33 crianças de três a cinco anos de idade sobre a definição da família e a sua função identificou que as crianças, em sua maioria, definiram a família de acordo com a sua composição. Destacaram as relações biológicas entre os membros, incluindo, na maior parte dos relatos, membros da família extensa. Além das relações de parentesco e consanguidade, elas acrescentaram pessoas com relações não biológicas e animais de estimação.

\section{Categoria 2 - A função da família}

A função da família para as crianças e os adolescentes foi adjetivada como fundamental, preponderante, importantíssima, total. Os participantes apontaram cinco funçôes principais: de apoio, de cuidados essenciais, educativa, afetiva e de orientação. Em relação à primeira, destacaram o suporte e a atenção oferecidos por aqueles a quem se pode recorrer e aqueles com quem se pode contar.

Uma família pra mim é alguém que a gente possa contar, em primeiro lugar. É quem a gente recorre sempre que precisa (p2).

A segunda função citada foi a de atender às necessidades básicas dos indivíduos, como alimentação, higiene, moradia, proteção e estimulação. A seguir, também foi apontado como papel da família na educação. Formalmente, de ofertar a educação formal e a vivência escolar. Informalmente, de transmitir valores e estabelecer limites, baseados nos ensinamentos sobre o que é certo e o que é errado socialmente. Acrescenta-se a isso, ainda, o carinho, o afeto, o amor e o respeito, que favorecem o desenvolvimento de laços afetivos positivos. 
É o que dá o suporte básico para a criança. Provê alimentação, o cuidado, impres-

cindível, o carinho, o afeto, até para o crescimento, desenvolvimento dessa criança. Proteção, depois mais adiante, a questão da educação. Acho que esse é o papel até que essa criança se torne um adolescente, um adulto e fique independente (p3).

Por último, a família desempenha ainda a função de orientação, oferecendo um modelo de identificação, mas também possibilitando que as crianças possam se conhecer, se entender e aprender a se comunicar com o mundo.

A família da criança, assim, é a base pro desenvolvimento dela, é de onde a criança tira as referências, os modelos, as possibilidades de identificação com modelos bons e maus. Então a família é que funda o desenvolvimento do sujeito, da criança; onde se dão as principais relações afetivas no início da vida (p9).

Todas essas funções foram apresentadas pelos participantes como essenciais para o crescimento (físico) e o desenvolvimento (psicossocial) das crianças e dos adolescentes. Desse modo, elas visam à saúde dos indivíduos, proporcionando autonomia, independência e responsabilidade diante da sociedade.

Bom, sem dúvida nenhuma é o espaço onde essa criança vai se desenvolver e vai ser o alicerce, vai ser a base para essa criança ou adolescente, vislumbrando a sua chegada na vida adulta de uma forma mais saudável, mais segura nas suas diversas escolhas, afetivas, profissionais, sexuais, o que for, na verdade. [...] Então é a base de tudo, é o alicerce, é a estrutura, é o norte, né (p4).

Os participantes, dessa forma, destacam a centralidade da família para o desenvolvimento humano. No ambiente familiar, estabelecem-se os vínculos primários que dão origem à personalidade e à saúde mental (BOWLBY, 2006). É, principalmente, no período da infância que se inicia o processo de constituição psíquica e a estruturação dos recursos internos para enfrentar as demandas da vida (FREUD, 2006a). Esse processo é fortemente influenciado pelo conjunto de funções materna e paterna.

Segundo Winnicott (2011), a função materna é exercida normalmente pela mãe, mas pode ser exercida por seu substituto no caso de ausência desta. Consiste na apresentação do objeto (intermediando e apresentando a criança para o mundo externo e seus objetos), holding (presença física e emocional no cuidado) e handling (o contato físico).

A função materna diferencia-se da maternagem, na medida em que a segunda é uma função universal e consiste em atender às necessidades básicas das crianças conforme o seu desenvolvimento, enquanto a primeira implica uma relação particular e um olhar individualizado entre a mãe (ou seu substituto) e o bebê 
(BARBOSA, 2010). Complementarmente, a função paterna consiste em apoiar, inicialmente, a relação da mãe com o bebê. Esse apoio oferece um suporte presencial, mas também financeiro (WINNICOTT, 2012).

Considerando o exposto, pode-se perceber que, nas suas falas, os participantes abordaram os aspectos essenciais das funções materna e paterna, embora não tenham feito uma relação direta dessas funções com os membros da família ou com o gênero feminino ou masculino.

Ainda ao encontro desses resultados, o estudo de Dessen e Ramos (2010) mostrou que as crianças definiram como funções da família o provimento material, o cuidado, o estímulo à socialização e o afeto. No mesmo trabalho, os participantes também foram questionados sobre o significado de famílias boas e más. Os resultados mostraram que as crianças definem uma família boa como aquela que consegue exercer essas funções citadas, enquanto a família má seria aquela que não as exerce.

\section{Categoria 3 - A configuração familiar mais frequente}

A terceira categoria empírica diz respeito à internação pediátrica e às configurações familiares mais presentes naquele ambiente. Primeiramente, os participantes descreveram as famílias como desfeitas, desestruturadas e em processo de falência das relaçôes. Exemplificaram com situações em que há apenas uma pessoa acompanhando a criança internada, outras em que as crianças estão sem família e abandonadas, ou ainda famílias em que a criança circula por diversos cuidadores. Identificam-se, dessa forma, muitas famílias ausentes ou monoparentais, em que o núcleo familiar é constituído pela criança e/ou seus irmãos e um dos pais (OLIVEIRA, 2009).

Ao contrário, também foram identificadas famílias muito grandes, com muitos "agregados", em que a família nuclear vive juntamente com membros da família extensa. Segundo Fonseca (2005), a noção de família varia conforme a categoria social com a qual estamos lidando, então é importante que consideremos o perfil socioeconômico da população atendida nos hospitais públicos.

Nas últimas décadas, houve uma diminuição significativa do número de filhos por mulher em todo o Brasil e em todas as camadas sociais. Apesar disso, a média de filhos por mulher ainda é maior nas famílias com renda per capita de até um salário mínimo (IBGE, 2009). Essas famílias também possuem uma 
cobertura menor por plano de saúde privado (IBGE, 2009), sendo as maiores usuárias do SUS.

Essa condição vai ao encontro de parte importante das famílias atendidas pelos profissionais entrevistados. Ao contrário das famílias mais ricas, que tendem a centrar-se e preservar a família nuclear, excluindo membros problemáticos e afastando a família extensa, os grupos populares apresentam uma dinâmica diferente. Estendem-se as relações familiares íntimas para padrinhos, vizinhos, primos, tios, amigos, etc., aumentando a rede apoio e facilitando a sobrevivência familiar (FONSECA, 2005).

Outra configuração que também foi citada foram as famílias polinucleares ou reconstituídas, que se caracterizam pela separação do casal ou divórcio e consequente recasamento. Dessa forma, são inseridos na vida das crianças e adolescentes papéis de madrasta e padrasto (LOBO, 2009), muito comuns na internação pediátrica, segundo os participantes. De qualquer forma, há uma distinção importante entre a família com quem a criança convive em casa e a família que a acompanha na internação hospitalar. Essa diferença foi claramente pontuada da seguinte fala:

[...] porque o que está aqui dentro, o que a gente mais vê são realmente as mães. Até acontece de pais e outros familiares acompanharem as crianças, mas eu acho que muito mais as mães do que outros. E, em casa, é tão variado, meu Deus! Avós junto, mães com padrastos, ou pai com madrastas, tias e tios morando na mesma casa, bem variado (p6).

Pode-se depreender disso que são distintas as configurações familiares das crianças internadas, porém as mães seguem identificadas como as mais presentes no cuidado em saúde. A citação a seguir corrobora o discurso anterior, na medida em que identifica a presença da mãe, mas não restringe a família a ela:

O mais comum é a mãe representando a família (p8).

Desse modo, a mulher segue como principal cuidadora, sendo mais comum encontrá-la ao lado dos pacientes. Além disso, na ausência da mãe, a substituta segue sendo uma figura feminina: avó, tia, vizinha, madrinha.

É óbvio que a gente ainda tem enraizado esse contexto de ter principalmente a figura feminina aí. Essa questão de gênero, sendo a mulher ainda a mãe, a principal cuidadora. E às vezes se ampliando ainda no sexo feminino para as avós, que têm tido um papel extremamente importante, as madrinhas, as tias, enfim, outras configurações. Mas eu vejo muito ainda do gênero feminino assumindo esse cuidado principal (p4). 
Ao mesmo tempo, ainda na questão de gênero, os profissionais identificam os pais como provedores, especialmente financeiramente.

\footnotetext{
Na verdade, a gente tem diferentes tipos de família aqui. Na grande maioria das vezes, quem acaba acompanhando os pacientes sãos as mães. [...] A mãe como principal cuidadora, pelo menos nos cuidados relacionados à saúde. O pai que provém toda parte financeira. Se um dos dois necessita deixar de trabalhar por causa de uma doença na família, acaba sendo a mãe que vai dar todos esses cuidados (p7).
}

Desse modo, apesar de a categoria anterior problematizar o exercício das funçôes materna e paterna para múltiplos atores, aqui, vê-se que as famílias que têm se feito presentes na internação pediátrica seguem o perfil tradicional. A mulher responsabiliza-se pela função materna e o homem, pela função paterna, assumindo o papel de provedor e, segundo o participante $\mathrm{n}{ }^{0} 5$, "oferecendo equilíbrio e um suporte necessário aos cuidados prestados pela mãe ao filho".

Nesse sentido, pode-se identificar uma variedade de discursos e contextos, conferindo ao tema da família um movimento constante, ainda permeado de modelos tradicionais, modernos e contemporâneos. Em relação a esse movimento, os participantes referem que, apesar da predominante presença feminina, há um número pequeno, mas crescente, de homens assumindo uma participação mais efetiva nos cuidados em saúde dos filhos. Ainda assim, a presença masculina no cuidado em saúde é mais incipiente.

Tem alguns [casos], acho que aumentou e tem aumentado muito, a presença do pai como cuidador, eu acho que isso em alguns casos é bem forte (p1).

\section{Categoria 4 - Implicações para o trabalho em saúde}

$\mathrm{Na}$ quarta categoria, os profissionais trouxeram as implicações das diferentes configurações familiares para o trabalho em saúde na internação pediátrica. Conforme a categoria teórica prévia, o trabalho é a atividade vital de criação de bens materiais e simbólicos, construídos socialmente, necessários para a sobrevivência da sociedade (ANTUNES, 2011), sendo a saúde um bem aqui incluído. $\mathrm{O}$ trabalho em saúde tem a especificidade de ser um trabalho vivo em ato, no qual a determinação do cuidado se dá no exato momento em que ele é executado (MERHY; FRANCO, 2008), implicando necessariamente o encontro entre trabalhadores e pacientes. No caso do trabalho com crianças e adolescentes, soma-se a esse encontro, necessariamente, a família (OLIVEIRA; SOMMERMAN, 2008). 
Segundo os profissionais entrevistados, o trabalho se dá independentemente de quem é a família, de quem são seus membros e de quais funções cada um executa dentro do grupo.

Na verdade, o que a gente mais trabalha aqui é com a pessoa que estiver acompanhando essa criança, às vezes é a mãe, às vezes é o avô, às vezes é a tia. Mas o nosso trabalho vai ser com a criança e com essa pessoa que estiver responsável por ela, independente de qual for a ligação sanguínea com essa criança (p6).

A seguir, pode-se perceber que as implicações citadas pelos profissionais para o seu trabalho variavam, mais significativamente, conforme a presença e a ausência da família. Os participantes apontaram o contato inicial como um momento de avaliação das potencialidades e fragilidades do paciente internado.

Então uma das principais coisas que a gente avalia quando a gente está entrando no atendimento de uma criança é de como é que aquela família se constitui, como é que a gente vai poder contar com aquela rede familiar, ou com a ausência dela (p9).

Os profissionais referem que, ao longo dos atendimentos, buscam identificar as pessoas de referência para aquela criança ou adolescente:

Geralmente a gente busca saber quem vão ser os cuidadores dessa criança, 'os' e não 'a' cuidadora (p8).

Nesse sentido, pode-se entender que os profissionais não centralizam os cuidados em saúde num único ou específico membro da família.

A relação que se estabelece a partir do encontro entre profissionais, paciente e família, pode facilitar ou dificultar o tratamento. A estrutura da família, já citada anteriormente, influencia na qualidade dessa relação, podendo contribuir ou não para o desgaste dos profissionais (ARAÚJO et al., 2002). Quando a família está presente e consegue cumprir suas funções, esse encontro favorece e potencializa a recuperação da saúde (ROMANO, 2008):

E muda muito com uma família bem estruturada [...] Parece que tudo funciona com mais harmonia, mesmo com casos bastante graves (p5).

Por outro lado, quando a família é ausente, desestruturada ou vulnerável psicossocialmente, esses fatores podem influenciar negativamente nos processos de saúde e doença, inclusive aumentando o tempo de internação (FAVARATO; GAGLIANI, 2008).

Muitas vezes, dependendo da família, interfere diretamente no cuidado da criança. A gente trabalha muito com criança com doença crônica, e a gente precisa que essa família tenha um envolvimento e que tenha uma disponibilidade de poder estar pre- 
sente no hospital, aprender o cuidado com a criança [...] e isso interfere diretamente no prognóstico da criança e nesse tratamento, até no tempo de internação. Muito frequentemente, a criança está bem, em condições de alta, e não vai para casa por causa dessa questão familiar (p3).

De qualquer forma, os profissionais se veem diante da tarefa de lidar com essa variedade de formações familiares contemporâneas, ampliando o olhar sobre elas e buscando compreendê-las. Com efeito, os entraves para o trabalho se dão pela ausência e não pela diversidade da presença.

[...] às vezes tem um impacto maior no momento, mas o que o tempo te mostra é que, indiferente da configuração, o importante é o cuidado que possa se estabelecer com essa criança. O principal é esse olhar, é essa referência, seja ela pai, mãe, tia, avó, mas qual é efetivamente o papel dela de atender as necessidades do desenvolvimento, para o cuidado dessa criança $(\mathrm{p} 4)$.

Eu acho que muitas vezes a gente pega casos que as crianças não têm nenhuma estrutura, isso é muito comum aqui. Tem pai e tem mãe, mas eles não têm nenhuma atenção, nenhum cuidado, então, não tem nem a estrutura básica que a gente possa pensar para uma criação. Daí entra toda aquela situação em que o serviço social e a psicologia se envolvem e têm que pensar o que podem fazer para melhorar a situação da criança. [...] São as [situaçôes] mais difíceis da gente conseguir trabalhar (p2).

Nessas situações de ausência e maior vulnerabilidade, em que as funções materna e paterna não são satisfatoriamente exercidas, os profissionais sentem-se impelidos a desenvolvê-las, em um movimento de substituição do papel parental.

Então a gente vê que aquelas crianças ou aqueles adolescentes que têm pelo menos algum apoio desenvolvem aqui muito melhor e tem uma melhora mais significativa do que aqueles que não têm apoio de ninguém [...] Então isso acaba sendo ruim para a equipe porque a gente acaba assumindo papel de família e não deveria (p1).

Historicamente, os cuidados em saúde foram atribuídos a mulheres, que exerciam atividades no trabalho semelhantes às exercidas em casa: alimentar, lavar, limpar, etc. (ARAÚJO et al.; 2002). Não surpreende, portanto, que a fala citada seja de uma profissional do sexo feminino, que sente, no seu trabalho, a necessidade de assumir o papel parental na sua ausência.

Nesses casos, reúnem-se três importantes fatores: a condição de desamparo infantil (FREUD, 2006b), o adoecimento como um agravante desse desamparo e ausência da família como uma vulnerabilidade que agrega complexidade. Essa conjunção de fatores estabelece uma situação em que o trabalhador se sente convocado a (tentar) substituir a função materna e paterna. Dessa forma, o trabalhador fica exposto, em risco de vulnerabilidade psíquica, na medida 
em que assume para si uma demanda que não lhe pertence, fragilizando, por consequência, a sua capacidade de lidar com o trabalho.

Quando o trabalhador assume uma responsabilidade que não lhe cabe, é gerada uma sobrecarga psíquica. Por carga psíquica, compreendem-se os recursos afetivos relacionados ao sentido atribuído à tarefa e outros aspectos da relação que os trabalhadores estabelecem individual e coletivamente com o seu trabalho (LAURELL, 1989). Portanto o aumento da carga psíquica caracteriza-se pelo processo de trabalho em que o sujeito é levado a assumir uma carga superior à sua capacidade, podendo conduzir ao adoecimento (DEJOURS, 2007). A sobrecarga psíquica também implica esse reconhecimento, o da impossibilidade de atender determinadas demandas (OSORIO, 2006). Em estudo realizado com trabalhadores do Serviço de Emergência de um hospital geral, identificou-se que os próprios profissionais colocam-se em uma situação de desamparo quando assumem para si tais demandas (SILVA; RAMOS, 2014).

Em outro estudo, realizado com trabalhadores da ESF, os autores concluíram que, para que seja oferecido à população um serviço satisfatório, incluindo resolutividade, integralidade e humanização do atendimento, a saúde mental dos trabalhadores é fator essencial no sucesso (KATSURAYAMA et al.; 2013).

\section{Considerações finais}

Este trabalho buscou articular as temáticas das novas configurações familiares e do trabalho em saúde na pediatria de um hospital geral. Identificou-se que os trabalhadores das unidades hospitalares de atendimento a crianças e adolescentes estudadas reconhecem, no seu cotidiano, a presença de diferentes arranjos familiares, tanto dentro, quanto fora do hospital.

Nesse sentido, foi possível depreender dos discursos uma situação de vulnerabilidade psíquica dos trabalhadores associada à identificação de demandas que vão além do trabalho prescrito. Destaca-se a ausência da família como uma dessas situações, onde os profissionais são convocados a exercer as funções materna e paterna, fora daquilo que é possível para os profissionais da saúde.

Sugere-se a realização de estudos que abranjam outros hospitais e instâncias de cuidado à saúde da criança, visando o mapeamento das demandas na interface com as famílias, assim como as estratégias e possibilidades de enfrentamento para o trabalhador da saúde. ${ }^{2}$ 


\section{Referências}

ANTUNES, R. Trabalho. In: CATTANI, A.D.; HOLZMANN, L. (Org.). Dicionário de Trabalho e Tecnologia. Porto Alegre: UFRGS, 2011. p. 432-437.

ARAÚJO, M.D. et al. Formas de produzir saúde no trabalho hospitalar: uma intervenção em psicologia. Cadernos de Psicologia Social do Trabalho, v. 5, p. 37-49, 2002.

BARBOSA, D.C. O bebê e a creche: pode-se falar em função materna? In: BARBOSA, D. C.; PARlato-OliveIRA, E. (Org.). Psicanálise e Clinica com Bebês: Sintoma, Tratamento e Interdisciplina na Primeira Infância. São Paulo: Instituto Langes, 2010.

BARDIN, L. Análise de conteúdo. Lisboa, Portugal: Edições 70, 1979.

BOWLBY, J. Cuidados maternos e saúde mental. São Paulo: Martins Fontes, 2006.

BRASIL. Declaração dos Direitos da Criança e do Adolescente Hospitalizados (Resolução no 41 de outubro de 1995). Diário Oficial [da] República Federativa do Brasil, Brasília, DF, 13 out. 1995.

Estatuto da Criança e do Adolescente. Diário Oficial [da] República Federativa do Brasil, Brasília, DF, 13 jul. 1990.

Política Nacional de Atenção Básica. Brasília, DF, 2012. Disponível em: <http://189.28.128.100/dab/docs/publicacoes/geral/pnab.pdf >. Acesso em: 10 out. 2014.

DE ANTONI, C. Coesão e hierarquia em famílias com história de abuso físico. 2005. 212 f. Tese (Doutorado em Psicologia) - Pós-Graduação em Psicologia de Desenvolvimento, Universidade Federal do Rio Grande do Sul, Porto Alegre, 2005.

DEJOURS, C. A psicodinâmica do trabalho na pós-modernidade. In: MENDES, A.M; LIMA, S.C.C. Diálogos em Psicodinâmica do Trabalho. Brasília: Paralelo, 2007.

DESSEN, M.A.; RAMOS, P.C.C. Crianças pré-escolares e suas concepções de família. Paidéia, Ribeirão Preto, v. 20, n. 47, p. 345-357, set-dez, 2010.

FAVARATO, M.E.C.S.; GAGLIANI, M.L. Atuação do psicólogo em unidades infantis. In: ROMANO, B. W. (Org.). Manual de psicologia clínica para hospitais. São Paulo: Casa do Psicólogo, 2008

FONSECA, C. Concepções de família e práticas de intervenção: uma contribuição antropológica. Saúde e Sociedade, São Paulo, v. 14, n. 2, p. 50-59, 2005.

FREUD, S. Três ensaios sobre a sexualidade. In: STACHEY, J. Um caso de histeria, Três ensaios sobre a sexualidade e outros trabalhos. Rio de Janeiro: Imago, 2006a, v. 7 (Edição Standard Brasileira das Obras Psicológicas Completas de Sigmund Freud).

(1930). O mal-estar da civilização. In: STACHEY, J. O futuro de uma ilusão, o mal-estar da civilização e outros trabalhos. Rio de Janeiro: Imago, 2006b, v. 13 (Edição Standard Brasileira das Obras Psicológicas Completas de Sigmund Freud). 
GOMES G.C.; OLIVEIRA, P.K. Vivências da família no hospital durante a internação da criança. Rev Gaúcha Enferm., Porto Alegre, v. 4, n. 33, p. 165-171, 2012.

HINTZ, H.C. Espaço relacional na família atual. In: CERVENY, C.M.O. (Org.). Família em movimento. São Paulo: Casa do Psicólogo, 2007.

INSTITUTO BRASILEIRO DE GEOGRAFIA E ESTATÍSTICA. Pesquisa Nacional por Amostra de Domicílios (PNAD). Sintese de Indicadores Sociais 2009. Rio de Janeiro: IBGE, 2010. Disponível em: <http:/www.ibge.gov.br/home/estatistica/populacao/ trabalhoerendimento/pnad2009/pnad sintese_2009.pdf> Acesso em: 10 jun. 2015.

KATSURAYAMA, M. et al. Trabalho e sofrimento psíquico na Estratégia Saúde da Família: uma perspectiva Dejouriana. Cad. Saúde Colet. Rio de Janeiro, v. 21, n. 4, p. 414-419, 2013. LAURELL, A.C.; NORIEGA, M. Processo de produção e saúde. São Paulo: Hucitec, 1989.

LOBO, C. Parentalidade social, fratrias e relaçôes intergeracionais nas recomposiçôes familiares. Sociologia, Problemas e Práticas, v. 59, p. 45-74, 2009.

MEHRY, E.E.; FRANCO, T.B. Trabalho em saúde. In: PEREIRA, I.B.; LIMA, J.C.F. (Org.). Dicionário da Educação Profissional em Saúde. Rio de Janeiro: EPSJV, 2008.

MINAYO, M.C. de S.; GOMES, R.; DESLANDES, S.F. (Org.). Pesquisa social: teoria, método e criatividade. Petrópolis: Vozes, 2008.

MINUCHIN, S. Famílias: funcionamento e tratamento. Porto Alegre: Artmed, 1982.

OLIVEIRA, D. et al. Impacto das Configurações Familiares no Desenvolvimento de Crianças e Adolescentes. Interação em Psicologia. Curitiba, v. 12, n. 1, p. 87-98, 2008.

OLIVEIRA, E.B.S. de; SOMMERMAN, R.D. G. A família hospitalizada. In: ROMANO, B. W. (Org.). Manual de psicologia clínica para hospitais. São Paulo: Casa do Psicólogo, 2008.

OLIVEIRA, N.H.D. Família contemporânea. In: Recomeçar: família, filhos e desafios [online]. São Paulo: Editora UNESP; São Paulo: Cultura Acadêmica, 2009. Disponível em: <http://books.scielo.org/id/965tk/pdf/oliveira-9788579830365-03.pdf>. Acesso em: 25 set. 2016.

OSORIO, C. Trabalho no hospital: ritmos frenéticos, rotinas entediantes. Cadernos de Psicologia Social do Trabalho, v. 9, n. 1, p. 15-32, 2006.

PAPALIA, D.E; FELDMAN, R.D. Desenvolvimento Humano. Porto Alegre: AMGH, 2013. ROMANO, B.W. (Org.). Manual de psicologia clínica para hospitais. São Paulo: Casa do Psicólogo, 2008.

ROUDINESCO, E. A família em desordem. Zahar: Rio de Janeiro, 2003.

SILVA, S.M; RAMOS, M.Z. Profissionais de saúde de um serviço de emergência hospitalar: discursividades em torno do cuidado. Physis: Revista de Saúde Coletiva. Rio de Janeiro v. 24, n. 3, p. 693-714, jul-set. 2014. 
SOUSA, L.D.D. et al. A família na unidade de pediatria: percepções da equipe de enfermagem acerca da dimensão cuidadora. Cienc. enferm. Concepción, v.17, n.2, 2011.

TRAD, L.A.B. A família e suas mutaçōes: subsídios ao campo da saúde. In: (Org.)

Família contemporânea e saúde: significados, práticas e políticas públicas. Rio de Janeiro: Editora Fiocruz, 2010.

VILLA, S.B. Os Formatos Familiares Contemporâneos: transformações demográficas. Observatorium: Revista Eletrônica de Geografia, v. 4, n. 12, p. 2-26, dez. 2012.

WAGNER, A. (Org.). Desafios psicossociais da família contemporânea: pesquisas e reflexões. Porto Alegre: Artmed, 2011.

WINNICOTT, D.W. A família e o desenvolvimento individual. São Paulo: Martins Fontes, 2011.

. Os bebês e suas mães. São Paulo: Martins Fontes, 2012.

\section{Notas}

${ }^{1}$ A presente pesquisa teve financiamento dos próprios pesquisadores, sendo produto do trabalho de conclusão da Residência Integrada Multiprofissional em Saúde do Hospital de Clínicas de Porto Alegre.

${ }^{2}$ E.F. Pereira Neto participou da concepção do tema e delineamento da pesquisa; coleta, análise e interpretação dos dados; redação do artigo e aprovação da versão a ser publicada. M. Z. Ramos e E. M. C. Silveira participaram da concepção do tema e delineamento da pesquisa, revisão crítica e aprovação da versão a ser publicada. 


\section{Family arrangements and implications for the health work with children in a hospital}

The family has gone through several transformations over time. Today one can see different family configurations, including uncles, grandparents, godparents. These groups are characterized by relations of mutual, direct, intense and lasting influence, which are internalized by its members. In healthcare, especially in the area of child health, there is an encounter of workers, patients and families. This study aimed, therefore, to investigate whether health professionals identify effects of different family configurations on their work. The research, qualitative and of exploratory nature, was conducted in the pediatric unit of a university hospital. The participants, selected by convenience, were professionals of the eight formations active in the higher level unit: physician, psychologist, physiotherapist, social worker, pharmacist, physical educator, dietitian and nurse.

Data were collected through semistructured interviews and interpreted through content analysis. The results were aggregated into four categories: "The concept of family", "The role of the family", "Most frequent Family configuration" and "Implications for health work". We noticed that workers recognize the presence of different family arrangements and suffer when identify demands that go beyond the prescribed work, such as exercising the maternal and paternal functions.

> Key words: family configurations; health work; pediatrics. 